\title{
DESIGN OF PASSENGERS VEHICLE BODY ON FIRE ACCIDENTS
}

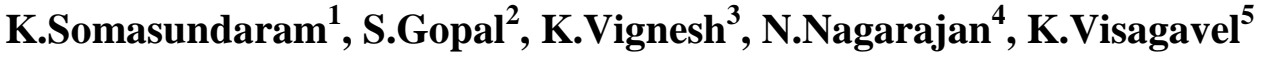 \\ ${ }^{1}$ Student, Mechanical Engineering, Knowledge Institute of Technology, Tamilnadu, India \\ ${ }^{2}$ Student, Mechanical Engineering, Knowledge Institute of Technology, Tamilnadu, India \\ ${ }^{3}$ Student, Mechanical Engineering, Knowledge Institute of Technology, Tamilnadu, India \\ ${ }^{4}$ Asst.Professor, Mechanical Engineering, Knowledge Institute of Technology, Tamilnadu, India \\ ${ }^{5}$ Professor\&Head, Mechanical Engineering, Knowledge Institute of Technology, Tamilnadu, India
}

\begin{abstract}
Generally Fire Accidents in Heavy Vehicles occur due to many reasons like Short Circuit of Electrical Connections, Bringing Flammable Materials and Indiscipline activities of People. So Passengers die in a large number including Children. It is mainly focused to safeguard the Passengers in Buses and Trains. During Fire Accidents, They have only two ways to escape, one is the Main Way and another is the Emergency Exit, so they cannot escape quickly and easily. By changing the Design of the body of the Vehicle, They can escape easily. By using the slider mechanism.
\end{abstract}

Keywords: Fire, Body of the Vehicle, Emergency Exit

\section{INTRODUCTION}

Body is the super structure for all vehicles. It may either be constructed separately and bolted to the chassis or manufactured integral with chassis (i.e. Frameless construction). The chassis and body make the complete vehicle.

A body consists of windows and doors, engine cover, roof, luggage cover etc. The electrical system in the body is connected to the chassis electrical units so that the battery and the generator can furnish the required electrical energy to the system.

\section{OVERVIEW OF THE PROJECT}

The main objective of our project is to protect passenger from fire accidents. Fire Accidents in heavy vehicles is a major issue. It occurs due to many reasons like Short Circuit of Electrical Connections, Bringing Flammable Materials and Indiscipline activities of People. Due to this, there is more human loss. During Fire Accidents, Passengers have only two ways to escape in vehicle, one is the Main way and another is the Emergency Exit. They cannot move easily and quickly.

In this system, the external sides of the body are designed as a slider which slides when the signal is received from sensor. During occurrence of fire, the temperature sensors sense the temperature and send signal to the Motor, which results in movement of slider and also manual operating system with glass guard provided with driver. So people can escape easily and quickly.

\section{TYPES OF VEHICLEBODY}

For different types of automobile vehicle, passenger space and overall dimensions vary. Various types of bodies for different vehicle can be listed as

$\begin{aligned} \text { i. } & \text { Buses } \\ \text { ii. } & \text { Car } \\ \text { iii. } & \text { Tanker } \\ \text { iv. } & \text { Jeep } \\ \text { v. } & \text { Tractor } \\ \text { vi. } & \text { Straight truck } \\ \text { vii. } & \text { Delivery van } \\ \text { viii. } & \text { Three wheeler (i.e. auto) }\end{aligned}$

\section{WORKING OF THE SYSTEM}

\subsection{General Working}

Initially, during occurrence of fire, there is a temperature sensor which senses the temperature of the body and gives a signal. By this signal the slider movement takes place. The Slider movement is controlled by a motor. As the signal reaches, the motor starts to operate and the Slider moves. The Power is transmitted from the Motor to slider by Chain. Now as the slider moves to an end, there will be a free space where it will be easy for the passengers to escape. 


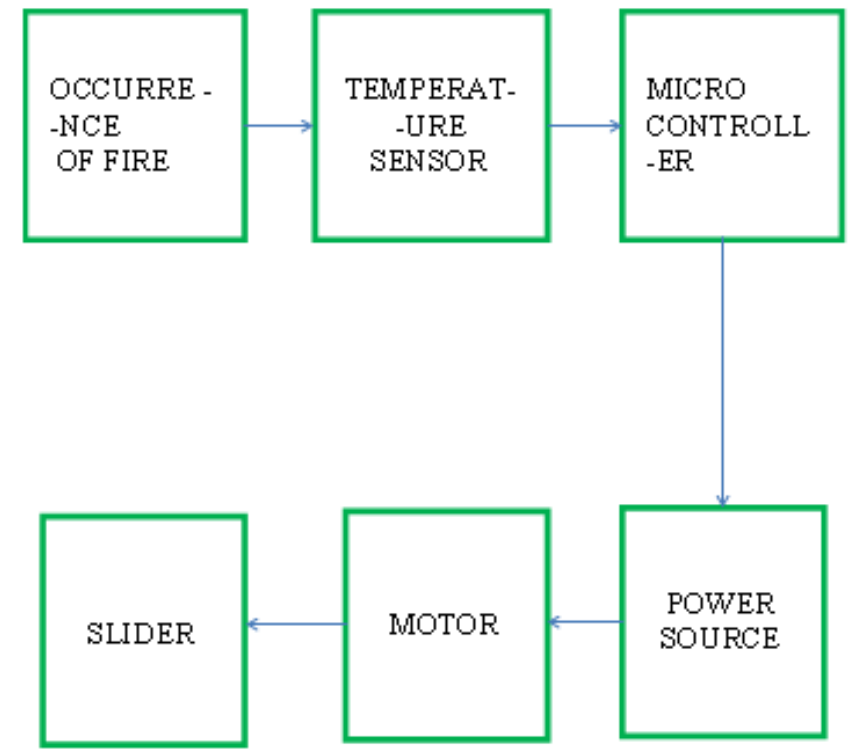

Schematic diagram of working

\subsection{Static Condition}

Initially, during occurrence of fire, there is a temperature sensor named LM35, which senses the temperature of the body and gives a signal. By this signal the slider movement takes place. The Slider movement is controlled by a Stepper DC motor. The drive and control of Motor is done by Microcontroller AT89652. As the signal reaches, the motor starts to operate and the Slider moves. The Power is transmitted from the Motor to slider by Chain. Now as the slider moves to an end, there will be a free space where it will be easy for the passengers to escape.

\subsection{Dynamic Condition}

In some cases, the vehicle may be in motion and Passenger may unable to get out of the vehicle during Fire. For certain conditions, the temperature sensor senses the temperature of the body and then it makes a signal. By this signal the fuel gets cut off by the Throttle Sensor and there will be no fuel going to the engine. Due to this the vehicle will remain in rest condition. Then the Microcontroller again controls and drives the motor. It will operate and make the slider to move, the movement is by Chain. By this passengers can escape easily and quickly.

\section{COMPONENTS}

The major components involved in this project for effective use of passenger vehicle body are as follows:

\section{Bus Body Attachment Components}

$\begin{array}{cl}\text { i. } & \text { Temperature SensorLM35 } \\ \text { ii. } & \text { Slider } \\ \text { iii. } & \text { Throttle Position Sensor } \\ \text { iv. } & \text { Stepper Motor }\end{array}$

Let us study about the functions and features in detail of the above components one by one which are as follows.

\subsection{Temperature SensorLM35}

The Temperature sensor is fixed in the vehicle, which can sense the temperature of the Vehicle. The LM35 series are precision integrated-circuit temperature sensors, with an output voltage linearly proportional to the Centigrade temperature. Thus the LM35 has an advantage over linear temperature sensors calibrated in ${ }^{\circ}$ Kelvin, as the user is not required to subtract a large constant voltage from the output to obtain convenient Centigrade scaling. The LM35 does not require any external calibration or trimming to provide typical accuracies of $\pm 1 / 4^{\circ} \mathrm{C}$ at room temperature and $\pm 3 / 4^{\circ} \mathrm{C}$ over a full $-55^{\circ} \mathrm{C}$ to $+150^{\circ} \mathrm{C}$ temperature range. Low cost is assured by trimming and calibration at the wafer level. The low output impedance, linear output, and precise inherent calibration of the LM35 make interfacing to readout or control circuitry especially easy. The device is used with single power supplies, or with plus and minus supplies. As the LM35 draws only $60 \mu \mathrm{A}$ from the supply, it has very low self-heating of less than $0.1^{\circ} \mathrm{C}$ in still air. The LM35 is rated to operate over a $-55^{\circ} \mathrm{C}$ to $+150^{\circ} \mathrm{C}$ temperature range, while the $\mathrm{LM} 35 \mathrm{C}$ is rated for a $-40^{\circ} \mathrm{C}$ to $+110^{\circ} \mathrm{C}$ range $\left(-10^{\circ}\right.$ with improved accuracy). The LM35 series is available packaged in hermetic TO transistor packages, while the LM35C, LM35CA, and LM35D are also available in the plastic TO-92 transistor package. The LM35D is also available in an 8-lead surface-mount small outline package and a plastic TO-220 package.

\section{Features}

- Calibrated Directly in ${ }^{\circ}$ Celsius (Centigrade)

- Linear $+10 \mathrm{mV} /{ }^{\circ} \mathrm{C}$ Scale Factor

- $0.5^{\circ} \mathrm{C}$ Ensured Accuracy $\left(\right.$ at $+25^{\circ} \mathrm{C}$ )

- Rated for Full $-55^{\circ} \mathrm{C}$ to $+150^{\circ} \mathrm{C}$ Range

- Suitable for Remote Applications

- Low Cost Due to Wafer-Level Trimming

- Operates from 4 to $30 \mathrm{~V}$

- Less than 60- $\mu \mathrm{A}$ Current Drain

- Low Self-Heating, $0.08^{\circ} \mathrm{C}$ in Still Air

- Nonlinearity Only $\pm 1 / 4^{\circ} \mathrm{C}$ Typical

- Low Impedance Output, $0.1 \Omega$ for $1 \mathrm{~mA}$ Load

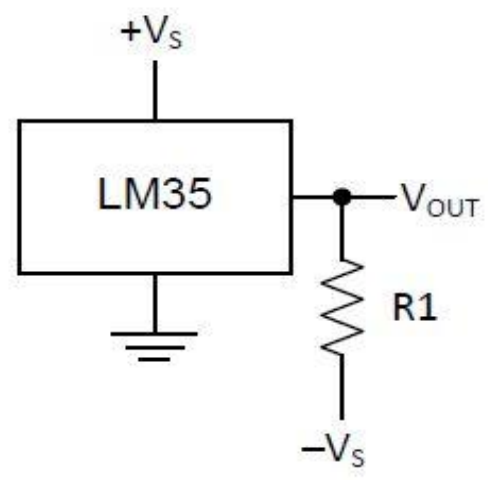

Choose $\mathrm{R}_{1}=-\mathrm{V}_{\mathrm{S}} / 50 \mu \mathrm{A}$

$V_{\text {OUT }}=1500 \mathrm{mV}$ at $150^{\circ} \mathrm{C}$

$V_{\text {OUT }}=250 \mathrm{mV}$ at $25^{\circ} \mathrm{C}$

$V_{\text {OUT }}=-550 \mathrm{mV}$ at $-55^{\circ} \mathrm{C}$ 


\subsection{Slider}

In this system, we are making the external sides of the body as a slider. Slider is nothing but a moving member, which slides when the signal is received. The slider also includes the window part of the vehicle. The slider is operated by a Stepper DC Motor. The Power is transmitted by the Stepper Motor to Slider by a Chain.

\subsection{Throttle Position Sensor}

A throttle position sensor (TPS) is a sensor used to monitor the position of the throttle in an internal combustion engine. The sensor is usually located on the butterfly spindle/shaft so that it can directly monitor the position of the throttle. More advanced forms of the sensor are also used, for example an extra closed throttle position sensor (CTPS) may be employed to indicate that the throttle is completely closed. Some engine control_units (ECUs) also control the throttle position electronic throttle control or "drive by wire" systems and if that is done the position sensor is used in a feedback loop to enable that control.

\subsection{Stepper Motor}

The stepper motor is an electromagnetic device that converts digital pulses into mechanical shaft rotation. The Typical Use of DC Stepper Motor is Position Control (Relative Position without Feedback). This type of stepper motor is good holding Torque.

\section{CONCLUSIONS}

Hence, by implementing this system large amount of Human Life can be saved. It can be implemented in AC coach buses, where more fire Accidents occur. Then we have better advantage to save the people.

\section{ACKNOWLEDGEMENTS}

This work was supported by Department of mechanical Engineering in Knowledge institute of technology. We are extremely grateful to thank our principal Dr.PSS.Srinivasan for providing all facilities to complete this project. The authors appreciate the support of Dr.K.Visagavel, Professor $\&$ Head- Department of Mechanical Engineering and Mr.N.Nagarajan, Asst. Professor, Mech.

\section{REFERENCES}

[1]. Rompe and Krüger, (1985). "Research On Emergency Exit System for bus safety". technical report.

[2]. Shiosaka and Kuboike, (1996). "Research on emergency exit system for school bus safety. Technical report 